\title{
Paracervical clamps for treatment of uncontrolled postpartum haemorrhage: a novel technique
}

\author{
Ramalingappa C. A., Durga Sireesha U.*, Shruthi B.
}

Department of Obstetrics and Gynecology, Karnataka Institute of Medical Sciences, Hubballi, Karnataka, India

Received: 22 March 2018

Revised: 12 June 2018

Accepted: 28 June 2018

\section{*Correspondence:}

Dr. Durga Sireesha U.,

E-mail: dr.sireesha7@gmail.com

Copyright: ( $)$ the author(s), publisher and licensee Medip Academy. This is an open-access article distributed under the terms of the Creative Commons Attribution Non-Commercial License, which permits unrestricted non-commercial use, distribution, and reproduction in any medium, provided the original work is properly cited.

\section{ABSTRACT}

Background: PPH is one of the most dreaded third stage complication and is one of the leading cause of maternal mortality and morbidity. Most of the deaths are due to limited availability of pharmacological agents and absent skills to manage PPH. The basis of the study is to introduce a novel technique of application of paracervical clamps transvaginally for temporary occlusion of uterine arteries which represent $90 \%$ of blood flow to the uterus.

Methods: A prospective study of patients with PPH who did not respond to medical management and who were hemodynamically stable. Paracervical clamps were applied and hemodynamic parameters are continuously monitored. Close monitoring for bleeding PV is done. Clamps are left intact for 6-8 hours and removed.

Results: Out of 680 cases of Post-partum haemorrhage. Paracervical clamps were applied to 320 patients from duration of 2013 to 2015 in Karnataka Institute of Medical Sciences and Sushruta Multispeciality Hospital Hubballi. Haemorrhage was effectively controlled in $304(95.1 \%)$ patients and only 16 patients required further surgical management. This non-invasive simple procedure has reduced the rates of surgical management of PPH and the associated morbidity.

Conclusions: Application of paracervical clamps is an effective, simple and minimally invasive surgical technique for avoiding excess blood loss in mild to moderate postpartum haemorrhage.

Keywords: Conservative management, Paracervical clamps, PPH

\section{INTRODUCTION}

Postpartum haemorrhage, defined as blood loss exceeding $500 \mathrm{ml}$ within 24 hours of delivery, is one of the most frequent causes of maternal mortality and morbidity globally and first most frequent direct cause of maternal death.

$\mathrm{PPH}$ contributes to $25 \%$ maternal deaths estimated to occur each year. Its incidence is about $5 \%$ of deliveries. Prevalence of postpartum haemorrhage is 6\%. Death from PPH occurs in about 1 per 1000 deliveries in low- resource countries compared with 1 in 100,000 deliveries in higher-resource countries. ${ }^{1}$

Postpartum hemorrhage (PPH) is the most important single cause of maternal death in both developing and developed countries. All pregnancies are at risk of $\mathrm{PPH}$ even if no predisposing factors are present.

Death from PPH occurs in about 1 per 1000 deliveries in low-resource countries compared with 1 in 100,000 deliveries in higher-resource countries. ${ }^{2}$ The majority of these deaths $(88 \%)$ occur within four hours of delivery, indicating that they are a consequence of events in the 
third stage of labour. The recurring theme of $\mathrm{PPH}$ is too little, too late. Because $\mathrm{PPH}$ is episodic in nature and almost always unexpected, birth attendants are not prepared to deal with it on a regular and recurring basis.

The World Health Organization (WHO) defines PPH as "blood loss greater than or equal to $500 \mathrm{ml}$ within 24 hours after birth", and severe primary PPH as "blood loss greater than or equal to $1000 \mathrm{ml}$ within 24 hours." Postpartum haemorrhage is the leading cause of maternal mortality, accounting for about $35 \%$ of all maternal deaths. About 14 million women around the world suffer from PPH every year (26 women every minute). The vast majority of these deaths occur in low and middle-income countries (LMICs). ${ }^{2}$

Concerns in developing countries are:

- Inability to diagnose PPH

- Limited availability of pharmacological agents (TXA, misoprostol, different preparations of oxytocin)

- Absent skills to manage PPH

- Neglecting the golden hour-Resuscitation.

The most common cause of primary PPH is uterine atony, the failure of the uterus to contract after delivery of the placenta. Other causes of PPH include genital tract trauma, uterine rupture, retained placental tissue, and maternal bleeding disorders. Haemorrhage is preventable in many cases with prenatal, labor and delivery, and postnatal interventions. Active management of the third stage of labor (AMTSL) is a multi-step procedure that has recently gained acceptance and global policies support its scale-up. In addition to other interventions, AMTSL includes administering a uterotonic after the delivery of the baby and before the delivery of the placenta to increase contraction of the uterus and prevent haemorrhage. If haemorrhage occurs either in the absence of AMTSL, or despite it, uterotonics can also be used to reduce the need for blood transfusions. However, blood transfusions may still be necessary management to save the lives of as many as $3 \%$ of cases of women with severe $\mathrm{PPH}^{3}$

There are three broad areas in which the outcomes from PPH may be improved: prevention, treatment, and rescue. Prevention covers antenatal strategies, active management of the third stage of labour, and treatments for retained placenta. PPH treatment covers both medical and surgical treatment, and PPH rescue therapies include intravenous fluids and blood transfusion, coagulation correction, and supportive care, such as compression garments.

The most common symptoms of PPH include uncontrolled bleeding, decreased blood pressure, increased heart rate, decreased red blood cell count, and swelling and pain in tissues in the vaginal and perineal area. Postpartum haemorrhage can be managed by medical, non-medical and surgical interventions. The WHO and other professional bodies recommend active management of the third stage of labor (AMTSL) for all vaginal births. Active management of the third stage of labor involves a prophylactic administration of uterotonics before delivery of the placenta in addition to other non-pharmacological interventions, such as late cord clamping and controlled cord traction of the umbilical cord. ${ }^{4}$

Most of the deaths and disabilities attributed to childbirth are avoidable, because the medical solutions are well known. Indeed, $99 \%$ of maternal deaths occur in developing countries that have an inadequate transport system, limited access to skilled care-givers and poor emergency obstetric services. It is axiomatic that each and every mother and newborn require care that is close to where they live, respectful of their culture and provided by persons with enough skill to act immediately should an unpredictable complication occur. The challenges that remain internationally are not technological but strategic and organizational. ${ }^{5}$

Objective of this study was to describe a novel, effective, simple and minimally invasive surgical technique for avoiding excess blood loss in postpartum hemorrhage in those patients in whom medical treatment has failed which provides following advantages;

- Timely intervention avoiding hysterectomy and consumption coagulopathy and preserves reproductive potential.

- Can be used in any setting-with or without facility.

- Prophylactic as well as therapeutic.

- Inexpensive, accessible and easy to use.

- Traumatic as well as atonic PPH can be managed.

- As temporary measures to shift the patient for further management from periphery.

\section{METHODS}

All patients of postpartum hemorrhage who were given medical treatment but not responding to medical treatment and are hemodynamically stable are selected after taking consent for paracervical clamps and all surgical intervention.

\section{Inclusion criteria}

Patients with failed medical treatment for postpartum hemorrhage fulfilling the following criteria-

- Hemodynamically stable

- Atonic or traumatic PPH

- Patients referred from outside as postpartum hemorrhage

- Women who wants to preserve reproductive potential

- Women giving informed written consent for all surgical intervention including paracervical clamp 
- Cases of post caesarean postpartum hemorrhage.

\section{Exclusion criteria}

- Hemodynamically unstable

- Suspected uterine rupture

- Cervical tears extending to lower segment.

\section{Method of study}

Present study was a clinical prospective study. Continuous monitoring of the haemodynamic parameters (pulse rate, blood pressure, ECG and $\mathrm{O}_{2}$ saturation) of the cases will be done using multiparameter monitor. Patients will be given continuous supplemental oxygen.

\section{Instruments required}

- 2 speculums

- 4 long ring/sponge forceps.

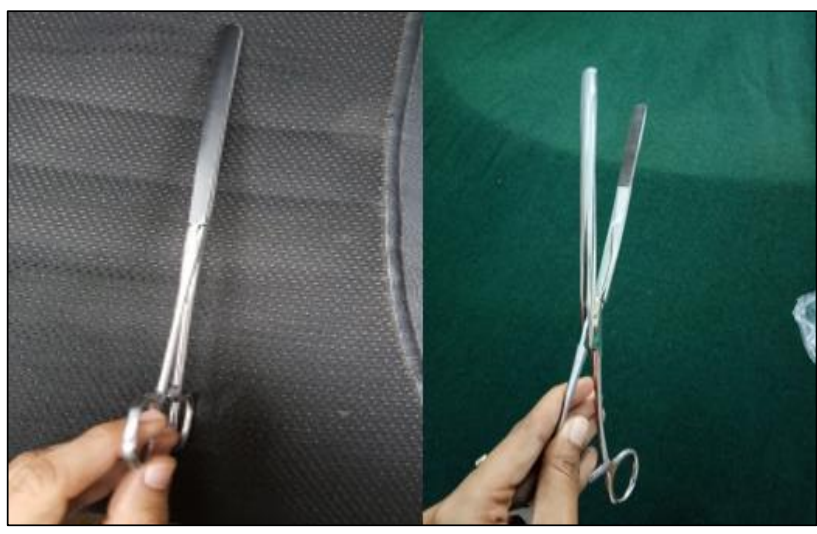

Figure 1: Paracervical clamps.

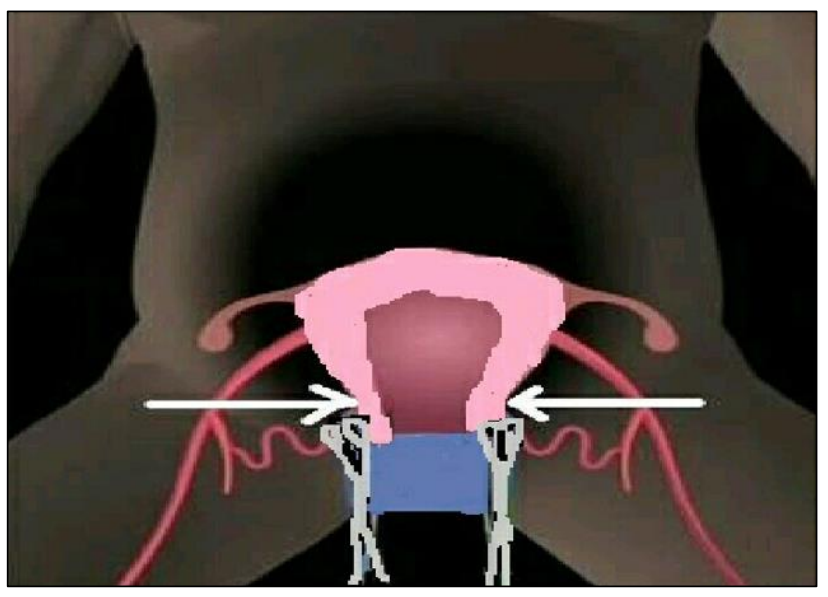

Figure 2: Site of occlusion of uterine artery with paracervical clamps.

\section{Basis}

Advancement of $1^{\text {st }}$ clamp applied during routine vaginal hysterectomy will include invariably uterine artery. After delivery uterus and cervix descends down. So uterines are accessible from below.

\section{Principle}

Temporary occlusion of uterine arteries which represent the source of $90 \%$ of blood flowing to the uterus.

\section{Procedure}

- Patient placed in lithotomy position

- Explore cervix

- Grasp anterior and posterior lip of cervix with help of ring/sponge forceps

- To occlude the right uterine artery, cervix is pulled to the left and sponge forceps/paracervical clamp is applied over tissue within the lateral fornix as much close to uterus and high up in hopes of occluding the uterine artery within the tissue bundles keeping in mind not to include ureter

- Forceps/clamps to be locked only by one lock

- Clamps can fold vagina back on the uterine arteries

- The procedure is repeated on opposite side

- Ring/sponge forceps holding anterior and posterior lip of cervix is removed

- Immediate stoppage of bleeding occurs. Patient is monitored continuously. Any fall in the hemodynamic status or if bleeding continues patient is taken for further surgical management.

- Forceps are kept for 6-8 hours and then removed.

- With these two clamps in place the blood flow to uterus through uterine arteries will be stopped. Cervical and vaginal tears sutured.

- USG and doppler study to know proper application and to ensure not to include ureters in first few cases.

\section{RESULTS}

Study done from January 2013 to June 2017. Table 1 shows age distribution of study subjects $(n=680)$. Majority of the patients i.e. $60.5 \%$ were from age group of 20-25 years. In the present study the mean age of patient was 25.1 years.

Table 1: Age distribution.

\begin{tabular}{|l|l|l|}
\hline Age group (years) & Total & Percentage \\
\hline$<20$ & 16 & 2.3 \\
\hline $20-25$ & 413 & 60.5 \\
\hline $26-30$ & 198 & 29.2 \\
\hline $31-35$ & 47 & 6.9 \\
\hline$>35$ & 6 & 1.0 \\
\hline
\end{tabular}

Table 2: Parity distribution.

\begin{tabular}{|ll|l|}
\hline Parity & Total & Percentage \\
\hline Primi & 332 & 48.7 \\
\hline G2 & 190 & 27.9 \\
\hline G3 and above & 158 & 23.3 \\
\hline
\end{tabular}


Table 2 shows distribution of study subjects according to parity $(n=680)$. Present study showed that $48.7 \%$ of the patients were primipara. $23.3 \%$ are gravida 3 and above.

Table 3: Mode of delivery.

\begin{tabular}{|lll|}
\hline Mode of delivery & Total & Percentage \\
\hline FTVD & 411 & 60.7 \\
\hline LSCS & 214 & 31.3 \\
\hline Instrumental delivery & 55 & 8 \\
\hline
\end{tabular}

Table 3 shows the distribution of study subjects according to mode of delivery $(n=680)$. In the present study of 680 cases of PPH, $411(60.7 \%)$ delivered vaginally and $214(31.3 \%)$ delivered by LSCS. 55(8\%) patients had instrumental delivery. Majority of the patients had vaginal delivery.

Table 4: Type of PPH.

\begin{tabular}{|c|c|c|}
\hline Type & Total & Percentage \\
\hline Atonic & 550 & 81 \\
\hline Traumatic & 100 & 14.6 \\
\hline Atonic +traumatic & 28 & 4.1 \\
\hline Broad ligament hematoma & 02 & 0.25 \\
\hline
\end{tabular}

Table 4 shows distribution of study subjects according to type of PPH $(n=680)$. Majority of the patients i.e. $81 \%$ had atonic PPH. Traumatic PPH was seen in $14.6 \%$. Combined atonic and traumatic PPH was seen in $4.1 \%$.

Table 5: Paracervical clamps applied.

\begin{tabular}{lll}
\hline & Total & Percentage \\
Clamps applied & 320 & 46.9
\end{tabular}

Table 5 shows out of 680 total PPH patients, clamps were applied to 320 eligible patients accounting to $46.9 \%$ Other 360 patients were managed by medical and surgical methods.

Table 6: Surgical management $(n=680)$.

\begin{tabular}{|lll|}
\hline & Total & Percentage \\
\hline STH & 115 & 16.9 \\
\hline Internal illiac artery ligation & 33 & 4.8 \\
\hline B lynch & 17 & 2.5 \\
\hline
\end{tabular}

Table 6 shows patients who underwent surgical management. Out of 680 patients 165 patients underwent alternative surgical management. These patients were not subjected to paracervical clamps but were taken for surgical management directly. Subtotal hysterectomy done in $16.9 \%$ patients, B Lynch sutures in $2.5 \%$ and Internal Illiac artery ligation done in $4.8 \%$ patients.

Table 7 shows distribution of study subjects according to further management in patients with paracervical clamps application $(\mathrm{n}=320)$.
Table 7: Outcome.

\begin{tabular}{|lll|}
\hline Outcome & Frequency & $\%$ \\
\hline Clamp successful & 304 & 95.0 \\
\hline $\begin{array}{l}\text { Required further surgical } \\
\text { procedure }\end{array}$ & 16 & 5.00 \\
\hline $\begin{array}{l}\text { Death } \\
\text { Total }\end{array}$ & 2 & 0.62 \\
\hline
\end{tabular}

Out of 320 study subjects paracervical clamps were successful in 304 patients. 16 patients required further surgical management. 2 patients succumbed to death.

\section{DISCUSSION}

The maternal mortality has been used traditionally as a measure of the quality of the health care. However, recently, the maternal morbidity, especially, the "near miss" morbidity, is being taken into account to assess the burden of the disease. Apparently, two-thirds of the obstetric morbidity is related to haemorrhage. It has been estimated that PPH increases the risk of the morbidity 50 times and that it has 5 times higher morbidity than the mortality. ${ }^{5}$

Application of paracervical clamps is a novel, effective, simple and minimally invasive surgical technique for avoiding excess blood loss in postpartum hemorrhage in those patients in whom medical treatment has failed. ${ }^{4}$ It provides timely intervention avoiding hysterectomy and consumption coagulopathy and preserves reproductive potential. It can be used in any setting-with or without facility. It is prophylactic as well as therapeutic. It is inexpensive, accessible and easy to use. Traumatic as well as atonic PPH can be managed.

It can be used as temporary measures to shift the patient for further management from periphery. Out of 680 patients 320 cases (except patients with intractable PPH and who were hemodynamically unstable) were managed with paracervical clamps. Patients who were hemodynamically stable with mild to moderate PPH were only taken as study subjects. Patients who had severe $\mathrm{PPH}$ and hemodynamically unstable were directly taken for surgical management.

Out of 320 cases, $304(95.1 \%)$ were successfully managed by paracervical clamps. PPH was not controlled in $16(4.8 \%)$ cases and they ultimately required surgical intervention.

Majority of the patients $60.5 \%$ were from age group of 20-25 years. In the present study the mean age of patient was 25.1 years which was less than the study by Gai et al which was $29.71 \pm 4.18$ years, and the study of Movafegh et al $(27.0 \pm 3.4$ years) and similar to the mean age in studies by Shekavat et al and Gungorduck et al which was 26 years; Gohel et al which was 24 years. ${ }^{6-10}$ 
Most common age group was 21 to 25 which accounts to $37.8 \%$ which was comparable to Al-Zirqi et al. ${ }^{11}$

Table 8: Comparison of age distribution with various studies.

\begin{tabular}{|ll|}
\hline Study & Age distribution \\
\hline Gai et al & $29.71 \pm 4.18$ years \\
\hline Movafegh et al & $27.0 \pm 3.4$ years \\
\hline Shekavat et al and gungorduck et al & 26 \\
\hline Al-zirqi et al & 22.5 \\
\hline Present study & 25.1 \\
\hline
\end{tabular}

$48.7 \%$ of the patients were primipara. Similar to the study conducted by Al-Zirqi I et al University of Oslo, Norway. ${ }^{6}$ Grand multiparous women were treated as a high-risk group and were accordingly managed vigilantly, which might be the reason for no significant association with haemorrhage. Another study conducted by Bhavana et al at Deccan College of Medical Sciences, Hyderabad, Telangana, India has similar results. ${ }^{12}$ The majority of patients being primipara and also similar to study by Gungorduck et al. But in the study by Gai et al and Gohel et al the gravidity of the patients was described where in mean gravidity was lesser in Gai et al study $(1.03 \pm 0.23$ vs. $1.04 \pm 0.23)$ compared to Gohel et al study $(2.1 \pm 0.95$ vs. $2.08 \pm 0.86)$.

Table 9: Comparison of association of parity with various studies.

\begin{tabular}{|ll|}
\hline Study & Parity \\
\hline Dr i al-zirqi et al & Primipara \\
\hline Bhavana et al at & Primipara \\
\hline Gungorduck et al & Primipara \\
\hline Gai et al & $1.03 \pm 0.23$ versus $1.04 \pm 0.23$ \\
\hline Gohel et al & $2.1 \pm 0.95$ versus $2.08 \pm 0.86$ \\
\hline Present study & Primipara \\
\hline
\end{tabular}

467 patients $(68.7 \%)$ had vaginal delivery. In a study conducted by Holm C. It is found that planned caesarean delivery is associated with a reduced risk of severe $\mathrm{PPH}$, as indicated by the use of RBC transfusions, compared with intended vaginal delivery.

$551(81 \%)$ patients had atonic PPH. The most common cause of PPH is atonicity of the uterus. Similar to a retrospective cohort study conducted by Mehrabadi A et al University of British Columbia and children and women health care of British Columbia, Canada. ${ }^{13}$

More liberal use of oxytocin during labour has been reported as a risk factor for PPH secondary to uterine atony possibly caused by uterine muscle receptors becoming desensitized. Use of Magnesium sulfate in few patients might have increased risk of PPH among women with pre-eclampsia and hypotonic uterus may be a possible side effect.
16 cases of failed paracervical clamps in management of atonic and traumatic PPH were managed surgically.

8 patients were primipara underwent B-lynch sutures and bilateral internal iliac artery ligation. 2 patients were primipara underwent peripartum hysterectomy. 5 patients were multipara underwent peripartum hysterectomy. Severe anemia was a major risk factor in all these factors.

2 patients succumbed to death due to DIC and MODS. 1 patient was multipara underwent subtotal hysterectomy for secondary PPH. The reason for failure of the cases would be improper application of paracervical clamps in 3 patients and worsening of hemodynamic status in 10 patients.

Present study showed higher success rates of $95 \%$ paracervical clamps as a non-invasive technique higher than a study which is a national cohort study conducted by Knight $\mathrm{M}$ et al, National Perinatal Epidemiology Unit, University of Oxford, Old Road Campus, Oxford, UK. In this study, $25 \%$ of women had successful intrauterine tamponade before the use of another second-line therapy. ${ }^{14}$

In another study conducted by Nahar et al in a tertiary care centre, Bangladesh 53 cases of PPH were managed by intrauterine balloon tamponade. ${ }^{15} 52$ out of 53 cases were successfully managed by balloon tamponade which accounts to $98 \%$.

In a comparable study done by Thirmur S et al, Russells Hall Hospital, Dudley Hospitals NHS Foundation Trust, Dudley, UK. ${ }^{16}$ Balloon tamponade was effective in 41 of 47 cases $(87.2 \%)$ of $\mathrm{PPH}$ from different causes such as uterine atony, placenta previa, and placental bed bleeding without further intervention. It was effective in avoiding hysterectomy in $93.6 \%$ women.

Table 10: Comparison of success rates with various studies.

\begin{tabular}{|lll|}
\hline $\begin{array}{l}\text { Balloon } \\
\text { tamponade study }\end{array}$ & $\begin{array}{l}\text { Successful } \\
\text { cases }\end{array}$ & Percentage \\
\hline $\begin{array}{lll}\text { Knight M et al } \\
\text { Nahar et al }\end{array}$ & 52 out of 53 & 98 \\
\hline Thirmur S et al & 41 out of 43 & 87.2 \\
\hline $\begin{array}{l}\text { Present study } \\
\text { (paracervical clamps) }\end{array}$ & 304 out of 320 & 95 \\
\hline
\end{tabular}

Haemorrhage was controlled successfully in only $36 \%$ of the women managed, as an initial second-line treatment, with pelvic vessel ligation including internal iliac artery or uterine artery ligation. The rationale for this treatment is based on the haemodynamic studies of Burchell, which showed that iliac artery ligation reduced pelvic blood flow and thus promoted haemostasis.

However, the reported success rate of internal iliac ligation varies from 40 to $100 \%$, and other studies have 
reported the procedure avoids hysterectomy in only $50 \%$ of cases. In the present study 3 cases of failed paracervical clamps underwent $b$ lynch and internal iliac artery ligation and 3 patients underwent peripartum hysterectomy.

Table 11: Comparison of uterine salvage in various studies.

\begin{tabular}{|lll|}
\hline Study & Duration & Uterine salvage \\
\hline Joshi VM et al ${ }^{17}$ & 13 years & $60.7 \%$ \\
\hline Nayak AK et al & 2 years & $73.4 \%$ \\
\hline Bangal et al ${ }^{18}$ & 15 years & $76 \%$ \\
\hline Mukherjee et al & 6 years & $83.3 \%$ \\
\hline Present study & 3.5 years & $95 \%$ \\
\hline
\end{tabular}

Joshi VM et al, KEM Hospital, Pune, India. Out of 84 patients undergoing prophylactic internal iliac artery ligation, 33 patients had hysterectomy and uterine salvage rate was $60.7 \%$. In a retrospective study conducted by Nayak AK et al, Shri Ramachandra Bhanj Medical College, Cuttack, Odisha, India, 45 cases of IIAL over a period of 2 years with a uterine salvage rate of $73.4 \%$. Bangal et al had done an analysis of 54 cases over a period of 15 years in a tertiary care center, Loni. Mukherjee et al, performed 36 cases of IIAL with a success rate of $83.3 \%$ in 6 years.

\section{CONCLUSION}

320 out of 680 cases of PPH in study who failed medical management and who were hemodynamically stable had received paracervical clamps.

Out of 320 cases only 16 patients required surgical management. Postpartum haemorrhage (PPH) is an obstetrical emergency which follows a delivery. It is a major cause of maternal morbidity, and one of the top three causes of maternal mortality.

Haemorrhage is the leading cause of the admissions to the intensive care unit and the most preventable cause of the maternal mortality. An efficient management by application of paracervical clamps can significantly reduce the need for surgical interventions in managing the post-partum haemorrhage.

Funding: No funding sources

Conflict of interest: None declared

Ethical approval: The study was approved by the Institutional Ethics Committee

\section{REFERENCES}

1. World Health Organization. Trends in maternal mortality: 1990-2015: estimates from WHO, UNICEF, UNFPA, World Bank Group and the United Nations Population Division: executive summary.
2. Carroli G, Cuesta C, Abalos E, Gulmezoglu AM. Epidemiology of postpartum haemorrhage: a systematic review. Best Practice Res Clin Obstet Gynaecol. 2008;22(6):999-1012.

3. Society of Obstetricians and Gynaecologists of Canada. Advances in labour and risk management (ALARM) course manual. $9^{\text {th }}$ ed. Ottawa, Ontario: Society of Obstetricians and Gynaecologists of Canada; 2002.

4. Weeks A. The prevention and treatment of postpartum haemorrhage: what do we know, and where do we go to next? BJOG. 2015;122(2):202-10.

5. B-Lynch C. Conservative surgical management. A Text Book of Postpartum Hemmorhage. $1^{\text {st }}$ ed. UK: Sapiens; 2006;287:298.

6. Gai MY, Wu LF, Su QF, Tatsumoto K. Clinical observation of blood loss reduced by tranexamic acid during and after caesarian section: a multi-center, randomized trial. Eu J Obstet Gynecol Reprod Biol. 2004;112(2):154-7.

7. Movafegh A, Eslamian L, Dorabadi A. Effect of intravenous tranexamic acid administration on blood loss during and after cesarean delivery. Int $\mathbf{J}$ Gynaecol Obstet Organ Int Fed Gynaecol Obstet. 2011;115:224-6.

8. Sekhavat L, Tabatabaii A, Dalili M, Farajkhoda T, Tafti AD. Efficacy of tranexamic acid in reducing blood loss after cesarean section. J Maternal-Fetal Neonat Med. 2009 Jan 1;22(1):72-5

9. Gungorduk K, Yıldırım G, Asıcıoğlu O, Gungorduk OC, Sudolmus S, Ark C. Efficacy of intravenous tranexamic acid in reducing blood loss after elective cesarean section: a prospective, randomized, doubleblind, placebo-controlled study. Am J Perinatol. 2011;28:233-40.

10. Gohel M, Patel P, Gupta A, Desai P. Efficacy of tranexamic acid in decreasing blood loss during and after cesarean section: a randomised case controlled prospective study. J Obstet Gynecol India. 2007;57:227-30.

11. Al-Zirqi I, Vangen S, Forsen L, Stray-Pedersen B. Prevalence and risk factors of severe obstetric haemorrhage. BJOG. 2008;115(10):1265-72.

12. Bhavana G, Abhishek MV, Mittal S. A study of risk factors of postpartum hemorrhage and indications for caesarean section. Int J Reprod, Contracept, Obstet Gynecol. 2017 Jan 5;5(6).

13. Mehrabadi A, Hutcheon JA, Lee L, Kramer MS, Liston RM, Joseph KS. Epidemiological investigation of a temporal increase in atonic postpartum haemorrhage: a population-based retrospective cohort study. BJOG. 2013;120(7):85362.

14. Knight M. Peripartum hysterectomy in the UK: management and outcomes of the associated haemorrhage. BJOG. 2007;114(11):1380-7.

15. Nahar N, Yusuf N, Ashraf F. Role of intrauterine balloon catheter in controlling massive PPH: experience in Rajshahi Medical College Hospital. Orion Med J. 2009;2:682-3. 
16. Tirumuru S, Saba S, Morsi H, Muammar B. Intrauterine balloon tamponade in the management of severe postpartum hemorrhage: A case series from a busy UK district general hospital. OJOG. 2013;3:131-6.

17. Joshi VM, Otiv SR, Majumder R, Nikam YA, Shrivastava M. Internal iliac artery ligation for arresting postpartum haemorrhage. BJOG: An Int J Obstet Gynaecol. 2007 Mar 1;114(3):356-61.
18. Bangal V, Kwatra A, Raghav S. Role of internal iliac artery ligation in control of pelvic hemorrhage. Pravara Med Rev. 2009;1(2):23-5.

Cite this article as: Ramalingappa CA, Sireesha DU, Shruthi B. Paracervical clamps for treatment of uncontrolled postpartum haemorrhage: a novel technique. Int J Reprod Contracept Obstet Gynecol 2018;7:3362-8. 